\title{
Heat of Polymerization of Alpha-Methylstyrene from Heats of Combustion of Monomer and Four Polymer Fractions
}

\author{
Donald E. Roberts and Ralph S. Jessup
}

\begin{abstract}
Measurements have been made with a bomb calorimeter of the heats of combustion $\left(-\Delta H c^{\circ}\right)$ at $25^{\circ} \mathrm{C}$ to form gaseous carbon dioxide and liquid water, of liquid alpha-methylstyrene (1-methyl-1-phenylethylene) and four fractions of its sold polymer having number average molecular weights of (I) 5,400 , (II) 3,750 , (III) 2,200 , and (IV) 1,300 . The values of heat of combustion are: monomer, $1204.87 \mathrm{kcal} / \mathrm{mole}$; fraction I, 1196.04; fraction II, 1195.83; fraction III, 1195.50; and fraction IV, $1194.74 \mathrm{kcal} / \mathrm{C}_{9} \mathrm{H}_{10}$ unit. Values of heats of polymerization $\left(-\Delta H p^{\circ}\right)$ at $25^{\circ} \mathrm{C}$ of liquid alpha-methylstyrene to its solid polymers have been calculated from the heats of combustion. The values of heat of polymerization are: fraction I, 8.83; fraction II, 9.04; fraction III, 9.37; and fraction IV, $10.13 \mathrm{kcal} / \mathrm{mole}$ of monomer. The standard deviations of the mean for heat of combustion are not more than $0.30 \mathrm{kcal} / \mathrm{mole}$, and for heat of polymerization, not more than $0.26 \mathrm{kcal} / \mathrm{mole}$. The decrease in heat of polymerization with increasing molecular weight is discussed. The low values of heats of polymerization are ascribed in part to steric interference between the substituent groups of the polymer chain.
\end{abstract}

\section{Introduction}

This project was undertaken in connection with a general investigation of molecular properties of high polymers, and as a sequel to the work on heat of polymerization of styrene [1]. ${ }^{1}$ The purpose was to determine the effect of the alpha-methyl group on heats of combustion and polymerization. It was known that alpha-methylstyrene (1-methyl-1-phenylethylene) does not polymerize readily (in absence of catalyst) $[2,3]$ and it was suspected that the steric interference between the substituent groups of the polymer chain might be partly responsible. A Fisher-Hirschfelder-Taylor molecular model of the polymer was made with the monomer units arranged head-to-tail, and alternating $d$ and $l$ units, that is, with $\mathrm{Me}$ and $\mathrm{Ph}$ groups interchanged, as follows:

$\begin{array}{cccccccc}\mathrm{H} & \mathrm{Me} & \mathrm{H} & \mathrm{Ph} & \mathrm{H} & \mathrm{Me} & \mathrm{H} & \mathrm{Ph} \\ --\mathrm{C}- & \mathrm{C}- & \mathrm{C}- & \mathrm{C}- & \mathrm{C}- & \mathrm{C}- & \mathrm{C}- & \mathrm{C}- \\ \mathrm{H} & \mathrm{Ph} & \mathrm{H} & \mathrm{Me} & \mathrm{H} & \mathrm{Ph} & \mathrm{H} & \mathrm{Me}\end{array}$

This model indicated that the molecule was so closely packed that it permitted only limited flexing or vibration and very little, if any, rotation. Ali models having other configurations (all head-to-tail) showed even higher degrees of interference. As a result of this steric effect, a low heat of polymerization was anticipated [4]. A second purpose of this work was to investigate the effect of molecular weight on the heat of polymerization.

\section{Methods and Apparatus}

The methods and bomb-calorimetric apparatus used in this work were the same as those described previously $[1,5,6$ to 10]. The observed value of heat of combustion in the bomb process, $-\Delta U_{\mathrm{B}}$, in each experiment was reduced to the value of $-\Delta U c^{\circ}$, the decrease in intrinsic energy accompanying the

Figures in brackets indicate the literature references at the end of this paper. combustion reaction

$$
\mathrm{C}_{9} \mathrm{H}_{10}(l \text { or } s)+\frac{23}{2} \mathrm{O}_{2}(g) \rightarrow 9 \mathrm{CO}_{2}(g)+5 \mathrm{H}_{2} \mathrm{O}(l),
$$

with each of the reactants and products in its thermodynamic standard state. The standard state for $\mathrm{C}_{9} \mathrm{H}_{10}$ in this equation is that of the liquid monomer or solid polymer. The procedure described by Washburn [11] for calculating the above reduction was modified so as to apply to $30^{\circ} \mathrm{C}$ and to the energy content of the gases at zero pressure.

The values of heat of combustion are based on the amount of the combustion reaction, obtained from the mass of carbon dioxide formed (molecular weight 44.010). No corrections were applied for unburned carbon in the crucible. In the few experiments in which carbon remained, it was found to be negligible in amount. Frequent tests, using a method described by Shepherd [12], revealed no carbon monoxide in the gaseous products of combustion.

The calorimetric system was calibrated with NBS Standard Sample $39 f$ of benzoic acid, using the value for the heat of combustion of this sample under the conditions of the standard bomb process, $Q \mathrm{~B}=$ 26433.8 abs $\mathrm{j} / \mathrm{g}$ at $25^{\circ} \mathrm{C}$, obtained from the value reported previously $[8,13]$.

The energy unit used is the absolute joule. Conversion to the conventional thermochemical calorie was made by use of the relation [14] $1 \mathrm{cal}=4.1840$ abs j.

\section{Materials}

The alpha-methylstyrene monomer and polymer were obtained from the Dow Chemical Co. through the courtesy of D. R. Stull. The monomer was stored in a closed bottle in a refrigerator at about $11^{\circ} \mathrm{C}$ until it was introduced into glass bulbs preparatory to the combustion experiments. It contained no inhibitor of polymerization. 
Analysis of alpha-methylstyrene by the Mass Spectrometry Section ${ }^{2}$ of this Bureau gave the following results:

$$
\begin{aligned}
& \text { Alpha-methylstyrene______ } 99.6 \text { mole percent } \\
& \text { Styrene______ }
\end{aligned}
$$

The values given for heat of combustion of alphamethylstyrene in table 2 have been corrected for the presence of this amount of styrene, using the value previously found [1] for the heat of combustion of styrene.

The polymer used was formed during distillation of the monomer in the plant finishing still. No catalyst could be detected, although very minute amounts of some oxidation product in the iron still may have been present. The maximum temperature to which the material was subjected was about $50^{\circ}$ to $60^{\circ}$ C. After receipt at this Bureau, the sample of polymer was fractionated ${ }^{3}$ and reprecipitated, the final product being four fractions consisting of fine noncrystalline powders. In the fractionation process, the raw polymer was dissolved in distilled toluene to make a 1-percent solution and filtered. The solution was placed in a 20-liter spherical flask in a constant-temperature $\left(30^{\circ} \mathrm{C}\right)$ water bath. Methanol was added dropwise with stirring, and fractions were removed when the methanol concentration reached 40 percent (Fraction I), 60 percent (II), and 80 percent (III). The precipitates were allowed to settle for 1 to 3 days and took the form of a viscous liquid phase at the bottom of the flask. Fraction IV was obtained by evaporation of the remaining solution. Fractions I, II, and III were diluted to 1-percent solution with a mixture of toluene and a small amount of methyl ethyl ketone to prevent phase separation from absorbed water. The polymer fractions were reprecipitated from these solutions, by adding each solution dropwise to excess methanol in the approximate ratio of 1 to 20 . Fraction IV was diluted to 4-percent solution and precipitated in the ratio of 1 to 10 . The fractions were decanted, washed eight times with methanol and dried at $30^{\circ} \mathrm{C}$ and $0.001 \mathrm{~mm}$ of mercury for about 1 month. The above treatment of the polymers was such that monomer and lowest molecular weight polymer probably were removed.

The largest portion of the polymer yield was fraction II, lesser amounts were obtained for fractions III and IV, and fraction I was quite small.

The vacuum pump system used for drying the polymer fractions contained a trap immersed in liquid air located in the line between the pump and the vacuum chamber, where the polymer powders were placed. By means of this trap, removal of condensible material from the polymer was continued during periods when the pump was shut off (at night and on week ends). After evacuation had continued for about a month, the liquid air was removed from the trap, which was then pumped out to a pressure less than $10^{-4} \mathrm{~mm}$ of mercury. After this the stopcock between the pump and the trap

${ }^{2}$ Under the direction of F. L. Mohler.

3. The fractionation was done under the direction of S. G. Weissberg. was shut off, and observations of the pressure in the system were made with a McLeod gage over a period of about 3 weeks. The rise in pressure during this time corresponded to the evaporation of a few hundredths of a milligram per week of material, assumed to be methanol, from about 10 to $15 \mathrm{~g}$ of polymer.

After completion of the above treatment, the polymers were exposed to the atmosphere for about 3 months. A sample of about $3.85 \mathrm{~g}$ of Fraction III was then evacuated for 2 days at $50^{\circ}$ to $65^{\circ} \mathrm{C}$ and weighed immediately after removal from the vacuum chamber. It was found to have lost about $2.0 \mathrm{mg}$, all of which was regained upon exposure to the atmosphere for 6 days. It was concluded that all solvent and methanol probably had been removed from the polymer powders. Residual moisture would not affect the heat of combustion, as the results are calculated from the mass of $\mathrm{CO}_{2}$ formed by burning the sample.

The results of determinations of molecular weight, intrinsic viscosity, and oxygen content of the polyalpha-methylstyrene fractions are

\begin{tabular}{|c|c|c|c|}
\hline Fraction & Molecular weight & Intrinsic viscosity & Oxygen content \\
\hline & $\bar{M}_{n}$ & {$[\eta]=d l / g$} & Avg. wt. $\% \mathrm{O}_{2}$ \\
I & 5,400 & 0.102 & 0.039 \\
II & 3,750 & .065 & .047 \\
III & 2,200 & .039 & .085 \\
IV $\ldots$ & 1,300 & .036 & .050 \\
\hline
\end{tabular}

The molecular weights ${ }^{4}$ were determined by both cryoscopic and isothermal distillation methods [15] for each fraction. Good agreement between the results of the two methods was obtained. In the cryoscopic method 0.5 - to 0.7 -percent solutions in spectroscopic grade cyclohexane were used, and the lowering of the melting point was about $0.02^{\circ}$ to $0.1^{\circ}$ C. For the isothermal distillation, 5- to 15percent solutions in toluene were made and suspended by a glass dish in the vapor of the solvent at $30^{\circ} \mathrm{C}$. A modified method of measurement was used, in which the rate at which the solution gains weight is compared to the rate when a material of known molecular weight is in solution. These methods give approximate number average molecular weights. They correspond to average degrees of polymerization of 45.7 to 11.0 , which are not very large. Differences in heats of combustion per monomer unit for polymers having given differences in molecular weights are more likely to be measurable if the molecular weights are small. The low molecular weights of the polymer used here may be partly a result of the fact that the alpha-methylstyrene was polymerized at raised temperatures. Previous workers [2] have found it difficult to obtain polymers of alpha-methylstyrene of high molecular weight, except at very low temperatures.

The measurements of intrinsic viscosity ${ }^{5}$ were made by means of the Ubbelohde viscometer at

\footnotetext{
${ }^{4}$ Measured by D. J. Brawley and S. G. Weissberg.
} 
about $30^{\circ} \mathrm{C}$, with concentrations in distilled toluene ranging from about 0.5 to $2 \mathrm{~g} / 100 \mathrm{ml}$. These viscosity values are included only for relative comparison.

The oxygen contents ${ }^{6}$ of the purified polymer fractions were determined by a direct method developed at this Bureau [16]. In the procedure for oxygen analysis, adsorbed water and air were removed by sweeping the sample for 2 hours at $30^{\circ}$ to $50^{\circ} \mathrm{C}$ with pure helium.

The effect of the oxygen content of the polymer samples on the values of heat of combustion and heat of polymerization will depend on whether the oxygen is present in some inert impurity or is chemically combined with the polymer molecules. In the former case the effect of the oxvgen would be negligible. If the oxygen is chemically combined with the polymer, the values of heat of combustion will be too low, and the values of heat of polymerization will be correspondingly too high. From the oxygen contents of the polymer samples given above, it is estimated that if all the oxygen is combined with the polymer the effect would not be greater than 0.03 percent in heat of combustion, or about 4 percent in heat of polymerization.

Since it is not known whether any of the oxygen is chemically combined with the polymer, the results have not been corrected for combined oxygen. The presence of the oxygen in the polymer samples introduces some uncertainty into the results, in addition to that resulting from other causes. Allowance for this has been made in calculating the estimated over-all standard deviations. ${ }^{?}$

\section{Results}

The results of the calibration experiments are given in table 1 . Two series of calibration experiments were required because of repairs to the bomb. The results of heat of combustion measurements on

${ }_{7}^{6}$ Measured by F. W. MeCulloch and W. H. Smith.

${ }^{7}$ Standard deviation of the mean as used in tables 1 and 2 is defined as $\left[\left(\Sigma d^{2}\right) / n(n-1)\right]^{1 / 2}$, where $d$ is the difference between a single observation and the mean, and $n$ is the number of observations. In the case of the final values of heat of combustion given in table 3 , the values of standard deviation include the effect. of estimated systematic errors, as well as accidental errors. These values wer calculated from the relation

$$
s=Q\left[\left(s_{E} / E\right)^{2}+\left(s_{Q} / Q\right)^{2}+B^{2}+R^{2}\right]^{1 / 2},
$$

where $s_{E}$ is the standard deviation of the mean of the experiments with benzoic acid to determine $E$, the energy equivalent of the calorimetric system; $s_{Q}$ is the standard deviation of the mean of the results of the experiments to determine $\theta$ the heat of combustion of the sample; $B$ is an allowance of $5 \times 10^{-5}$ for the standard deviation of the value used for the heat of combustion of benzoic acid; and $R$ is an allowance of $2 \times 10^{-4}$ in the case of the polymer or $5 \times 10^{-5}$ for the monome calculations, and takes account of systematic errors associated with the impuritie in the polymer samples and the determination of the amount of the combustion reaction from the mass of carbon dioxide. The expression used in connection with the values in table 4 was

$$
s^{\prime}=\left[\left(s_{m}\right)^{2}+\left(s_{p}\right)^{2}\right]^{1 / 2} .
$$

In this expression $s_{m}$ and $s_{p}$ were calculated from the data of the heat of combustion measurements on monomer and polymer, respectively, by means of expressions of the form

$$
\begin{aligned}
& s_{m}=Q\left[\left(s_{B} / E\right)^{2}+\left(s_{Q} / Q\right)^{2}\right]^{1 / 2} \\
& s_{p}=Q\left[\left(s_{E} / E\right)^{2}+\left(s_{Q} / Q\right)^{2}+R^{2}\right]^{1 / 2}
\end{aligned}
$$
As used here $R$ is an allowance of $15 \times 10^{-5}$ for the errors associated with impurities
in the polymers. It is assumed that systematic errors in the value used for the in the polymers. It is assumed that systematic errors in the value used for the of the combustion reaction will cancel in taking the difference between the heats of combustion of polymer and monomer. the polymer and monomer for each experiment were calculated by using the appropriate mean of calibration series $\mathrm{A}$ or $\mathrm{B}$, depending on whether the

\begin{tabular}{|c|c|c|}
\hline \multicolumn{3}{|c|}{ Observed energy equivalent $(E)$ at $28.5^{\circ} \mathrm{C}$} \\
\hline & Series A & Series B \\
\hline & $\begin{array}{l}\quad a b s j /{ }^{\circ} \mathrm{C} \\
13793.2 \\
13792.6 \\
13794.4 \\
13792.0 \\
13791.7 \\
13792.7 \\
13789.8 \\
13791.5\end{array}$ & $\begin{array}{r}a b s j /{ }^{\circ} C \\
13780.6 \\
13783.8 \\
13782.8 \\
13781.6 \\
13783.6 \\
13788.0 \\
13786.4 \\
13785.1 \\
13783.0 \\
13787.4 \\
13786.6\end{array}$ \\
\hline $\begin{array}{l}\text { Mean } \\
\text { Standard deviation of mean a, } s_{E}\end{array}$ & $\begin{array}{r}13792.2 \\
0.5\end{array}$ & $\begin{array}{r}13784.4 \\
0.7\end{array}$ \\
\hline
\end{tabular}
combustion experiment was performed before or after the alteration of the bomb.

TABLE 1. Calibration of calorimeter with benzoic acid

a See footnote 7 .

The results of heat of combustion measurements are given in table 2 , where $-\Delta U_{\mathrm{B}}$ is the observed heat of combustion under the conditions of the bomb process: the temperature $\left(30^{\circ} \mathrm{C}\right)$ to which the reaction is referred, the mass $(1 \mathrm{~g})$ of water placed in the bomb before each experiment, the internal volume of the bomb $(377 \mathrm{ml})$, and the conditions specified in columns 1 and 2 of the table. The quantity $-\Delta U c^{\circ}$ is the reduced value, as explained in section II

The values obtained for the mass of carbon dioxide formed in combustion are lower than the corresponding values calculated stoichiometrically from the masses of samples burned, assuming that the composition of the samples is represented by $\left(\mathrm{C}_{9} \mathrm{H}_{10}\right)_{x}$. The average differences between observed and calculated masses of carbon dioxide are, for alphamethylstyrene 0.052 percent, and for poly-alphamethylstyrene fractions: I, 0.110 percent; II, 0.106 percent; III, 0.188 percent; IV, 0.082 percent. Frequent measurements of the carbon dioxide formed in combustion of Standard Sample 39f of benzoic acid yielded results in agreement with calculated values within about 0.016 percent. The observed deficiency of carbon dioxide in the case of alpha-methylstyrene can probably be attributed to air or moisture dissolved in the liquid. The deficiency in the case of the samples of poly-alphamethylstyrene is probably due to the presence of nonhydrocarbon material in the samples as an impurity.

In table 3 are given values of $-\Delta U \mathrm{c}^{\circ}$ per mole of $\mathrm{C}_{9} \mathrm{H}_{10}$ (or per monomer unit) derived from the mean values given in table 2 by taking 9 moles of carbon dioxide as equivalent to 1 mole of monomer, or the $\mathrm{C}_{9} \mathrm{H}_{10}$ unit of the polymer. There are also given in table 3 values of $-\Delta H c^{\circ}$, the decrease in heat content in the combustion reaction, with all reactants and products in their standard states. 
TABLE 2. Bomb-calorimetric measurements on poly-alphamethylstyrene and alpha-methylstyrene

\begin{tabular}{|c|c|c|c|c|}
\hline \multirow{2}{*}{$\begin{array}{l}\text { Mass of } \\
\text { sample }\end{array}$} & \multirow{2}{*}{$\begin{array}{l}\text { Initial } \mathrm{O}_{2} \\
\text { pressure at } \\
30^{\circ} \mathrm{C}\end{array}$} & \multirow{2}{*}{$\underset{\mathrm{CO}_{2}}{\text { Mass of }}$} & \multicolumn{2}{|c|}{$\begin{array}{l}\text { Heat of combustion at } \\
\qquad 30^{\circ} \mathrm{C}\end{array}$} \\
\hline & & & $-\triangle U_{B}$ & $-\triangle U c^{\circ}$ \\
\hline \multicolumn{5}{|c|}{ POLY-ALPHA-METHYLSTYRENE, FRACTION I } \\
\hline $\begin{array}{c}g \\
0.89655 \\
.95498 \\
.91254 \\
.96967 \\
.93899 \\
.98114\end{array}$ & $\begin{array}{l}\text { atm } \\
36.2 \\
36.5 \\
37.2 \\
33.9 \\
33.8 \\
33.2\end{array}$ & $\begin{array}{c}g \\
\text { 3. } 00141 \\
3.19689 \\
3.05418 \\
3.24617 \\
3.14361 \\
3.28476\end{array}$ & $\begin{array}{c}a b s j / g \mathrm{CO}_{2} \\
12628.3 \\
126253 \\
12620.7 \\
12620.5 \\
12616.8 \\
12620.2\end{array}$ & $\begin{array}{c}a b s j / g \mathrm{CO}_{2} \\
12621.7 \\
12618.4 \\
12613.7 \\
12613.9 \\
12610.3 \\
12613.7\end{array}$ \\
\hline \multicolumn{4}{|c|}{$\begin{array}{l}\text { Mean } \\
\text { Standard deviation of mean }{ }^{\mathrm{a}}, s_{Q}\end{array}$} & $\begin{array}{r}12615.3 \\
1.7\end{array}$ \\
\hline \multicolumn{5}{|c|}{ POLY-ALPHA-METHYLSTYRENE, FRACTION II } \\
\hline $\begin{array}{r}0.92370 \\
.95762 \\
.95526 \\
.98681 \\
.94285 \\
.96934\end{array}$ & $\begin{array}{l}35.9 \\
36.1 \\
36.7 \\
36.7 \\
36.5 \\
37.2\end{array}$ & $\begin{array}{l}3.09308 \\
3.20656 \\
3.19895 \\
3.30407 \\
3.15585 \\
3.24607\end{array}$ & $\begin{array}{l}12620.5 \\
12620.5 \\
12619.4 \\
12617.5 \\
12623.3 \\
12618.8\end{array}$ & $\begin{array}{l}12613.7 \\
12613.6 \\
12612.5 \\
12610.5 \\
12616.4 \\
12611.8\end{array}$ \\
\hline \multicolumn{4}{|c|}{$\begin{array}{l}\text { Mean } \\
\text { Standard deviation of mean a, } s_{Q}\end{array}$} & $\begin{array}{r}12613.1 \\
0.8\end{array}$ \\
\hline \multicolumn{5}{|c|}{ POLY-ALPHA-METHYLSTYRENE, FRACTION III } \\
\hline $\begin{array}{r}0.92886 \\
.93525 \\
.93816 \\
.96117 \\
.97595 \\
.94137\end{array}$ & $\begin{array}{l}32.6 \\
32.4 \\
32.5 \\
32.5 \\
32.7 \\
32.4\end{array}$ & $\begin{array}{l}3.10661 \\
3.12905 \\
3.13786 \\
3.21605 \\
3.26540 \\
3.15006\end{array}$ & $\begin{array}{l}12616.5 \\
12616.1 \\
12620.5 \\
12613.5 \\
12615.5 \\
12613.2\end{array}$ & $\begin{array}{l}12610.2 \\
12609.8 \\
12614.2 \\
12607.1 \\
12609.1 \\
12606.9\end{array}$ \\
\hline \multicolumn{4}{|c|}{$\begin{array}{l}\text { Mean } \\
\text { Standard deviation of mean }{ }^{a}, s Q\end{array}$} & $\begin{array}{r}12609.6 \\
1.1\end{array}$ \\
\hline \multicolumn{5}{|c|}{ POLY-ALPHA-METHYLSTYRENE, FRACTION IV } \\
\hline $\begin{array}{r}1.02726 \\
0.94887 \\
.98428 \\
.93562 \\
.95606 \\
.94128\end{array}$ & $\begin{array}{l}32.9 \\
33.0 \\
33.2 \\
32.9 \\
32.5 \\
32.5\end{array}$ & $\begin{array}{l}\text { 3. } 44043 \\
3.17777 \\
3.29671 \\
3.13345 \\
3.20232 \\
3.15200\end{array}$ & $\begin{array}{l}12610.7 \\
12608.1 \\
12607.1 \\
12607.6 \\
12608.6 \\
12605.9\end{array}$ & $\begin{array}{l}12604.2 \\
12601.7 \\
12600.6 \\
12601.2 \\
12602.2 \\
12599.6\end{array}$ \\
\hline \multicolumn{4}{|c|}{$\begin{array}{l}\text { Mean } \\
\text { Standard deviation of mean a, } s_{Q}\end{array}$} & $\begin{array}{r}12601.6 \\
0.6\end{array}$ \\
\hline \multicolumn{5}{|c|}{ ALPHA-METHYLSTYRENE, MONOMER } \\
\hline $\begin{array}{r}0.89208 \\
.80943 \\
.79325 \\
.74323 \\
.90776 \\
.90256\end{array}$ & $\begin{array}{l}32.7 \\
32.6 \\
32.6 \\
32.4 \\
32.2 \\
32.3\end{array}$ & $\begin{array}{l}2.98873 \\
2.71183 \\
2.65744 \\
2.48983 \\
3.04109 \\
3.02352\end{array}$ & $\begin{array}{l}12710.2 \\
12708.4 \\
12709.4 \\
12705.7 \\
12710.9 \\
12709.3\end{array}$ & $\begin{array}{l}12710.4 \\
12708.7 \\
12709.7 \\
12706.2 \\
12711.2 \\
12709.5\end{array}$ \\
\hline \multicolumn{4}{|c|}{$\begin{array}{l}\text { Mean } \\
\text { Standard deviation of mean a, } s_{Q}\end{array}$} & $\begin{array}{r}12709.3 \\
0.7\end{array}$ \\
\hline
\end{tabular}

a See footnote 7
For reducing the values at $30^{\circ}$ to corresponding values at $25^{\circ} \mathrm{C}$, the heat capacity of alpha-methylstyrene was derived from unpublished data obtained at the Bureau on the heat capacity of styrene [17], and an estimate of the increase in $C_{p}$ accompanying the addition of a $\mathrm{CH}_{2}$ group; the heat capacity of poly-alpha-methylstyrene was obtained from that of the monomer by use of the ratio of heat capacities [17], polystyrene: styrene.

Values of heat of polymerization of alpha-methylstyrene to give the four polymer fractions are shown in table 4. These values were obtained by taking the difference between the value of $-\Delta H c^{\circ}\left(25^{\circ} \mathrm{C}\right)$ (table 3) for the monomer, and the value for each of the polymer fractions.

TABLE 4. Values of heat of polymerization

\begin{tabular}{|c|c|c|}
\hline Fraction & $-\Delta H_{p}^{\circ}\left(25^{\circ} \mathrm{C}\right)$ & $\begin{array}{l}\text { Standard } \\
\text { deviation of } \\
\text { mean a, } s^{\prime}\end{array}$ \\
\hline $\begin{array}{l}\text { I } \\
\text { II } \\
\text { III } \\
\text { IV }\end{array}$ & $\begin{array}{r}\mathrm{kcal} / \text { mole } \\
8.83 \\
9.04 \\
9.37 \\
10.13\end{array}$ & $\begin{array}{r}0.26 \\
.22 \\
.23 \\
.22\end{array}$ \\
\hline
\end{tabular}

a See footnote 7 .

\section{Discussion}

The values of heat of polymerization given in table 4 are lower than the value $\left(-\Delta H p^{\circ}=16.7\right.$ $\mathrm{kcal} /$ monomer unit) previously reported for styrene [1], and are also lower than any value previously reported for a vinyl compound [18]. It has been suggested by Flory [19] and by Evans and Tyrrall [4] that low values of heat of polymerization of 1,1-disubstituted ethylenes are to be attributed to steric interference between the substituent groups. There are other effects that may be partly responsible for the low heat of polymerization, such as the effects of side groups on bond energies in the monomer as compared with those in the polymer, and the lack of a large "end effect", which in ethylene arises from the nearness of the double bond to the ends of the monomer molecule [18]. It is believed, however, that the magnitude of the latter two effects is not sufficient to account for the very low values of $-\Delta H p^{\circ}$ for alpha-methylstyrene, but that steric interference must be an important factor.

TABLE 3. Values of heat of combustion

\begin{tabular}{|c|c|c|c|c|c|c|c|c|c|c|}
\hline \multirow{3}{*}{ Quantity } & \multicolumn{8}{|c|}{ Poly-alpha-methylstyrene (solid) } & \multirow{2}{*}{\multicolumn{2}{|c|}{$\begin{array}{l}\text { Alpha-methylstyrene } \\
\text { (liquid) }\end{array}$}} \\
\hline & \multicolumn{2}{|c|}{ Fraction I } & \multicolumn{2}{|c|}{ Fraction II } & \multicolumn{2}{|c|}{ Fraction III } & \multicolumn{2}{|c|}{ Fraction IV } & & \\
\hline & $\begin{array}{c}\text { abs kj// } \\
\mathrm{C}_{9} \mathrm{H}_{10} \\
\text { unit }\end{array}$ & $\begin{array}{c}\mathrm{kcal} / \\
\mathrm{C}_{9} \mathrm{H}_{10} \\
\text { unit }\end{array}$ & $\begin{array}{c}\mathrm{abs} \mathrm{kj} / \\
\mathrm{C}_{9} \mathrm{H}_{10} \\
\text { unit }\end{array}$ & $\begin{array}{c}\mathrm{kcal} / \\
\mathrm{C}_{9} \mathrm{H}_{10} \\
\text { unit }\end{array}$ & $\begin{array}{c}\text { abs kj/ } \\
\mathrm{C}_{9} \mathrm{H}_{10} \\
\text { unit }\end{array}$ & $\begin{array}{l}\mathrm{kcal} / \\
\mathrm{C}_{9} \mathrm{H}_{10} \\
\text { unit }\end{array}$ & $\begin{array}{l}\text { abs kj/ } \\
\mathrm{C}_{9} \mathrm{H}_{10} \\
\text { unit }\end{array}$ & $\begin{array}{l}\mathrm{kcal} / \\
\mathrm{C}_{9} \mathrm{H}_{10} \\
\text { unit }\end{array}$ & $\begin{array}{c}\text { abs kj/ } \\
\text { mole }\end{array}$ & $\begin{array}{l}\mathrm{kcal} / \\
\text { mole }\end{array}$ \\
\hline $\begin{array}{l}-\Delta U c^{\circ}\left(30^{\circ} \mathrm{C}\right) \\
-\Delta H c^{\circ}\left(30^{\circ} \mathrm{C}\right) \\
-\Delta H c^{\circ}\left(25^{\circ} \mathrm{C}\right)\end{array}$ & $\begin{array}{l}4996.80 \\
5003.10 \\
5004.24\end{array}$ & 1196.04 & $\begin{array}{l}\text { 4995. } 93 \\
\text { 5002. } 23 \\
5003.37\end{array}$ & 1195.83 & $\begin{array}{l}4994.54 \\
5000.84 \\
5001.98\end{array}$ & 1195.50 & $\begin{array}{l}4991.37 \\
4997.67 \\
4998.81\end{array}$ & 1194.74 & $\begin{array}{l}5034.03 \\
5040.33 \\
5041.17\end{array}$ & 1204.87 \\
\hline Standard deviation of mean a, $s \ldots \ldots$ & 1. 24 & 0.30 & 1.10 & 0.26 & 1.15 & 0.27 & 1.09 & 0.26 & 0.53 & 0.13 \\
\hline
\end{tabular}


In general, it is found that molecular models of polymers of 1,1-disubstituted ethylenes indicate that steric interference is quite pronounced if the monomer units are joined head-to-tail but is much less for the head-to-head and tail-to-tail arrangement. The low values of $-\Delta H p^{\circ}$ for alpha-methylstyrene are therefore consistent with other evidence [20, 21] that polymers of 1,1-disubstituted ethylenes are formed by head-to-tail addition.

It will also be seen from table 4 that the values of heat of polymerization of alpha-methylstyrene decrease systematically with increasing molecular weight of the polymer. This was not expected, and it seems worth while to examine other pertinent information to see whether it is consistent with the observed variation of heat of polymerization with molecular weight of polymer.

It is well known [22] that the heats of formation of an homologous series of hydrocarbons, either liquid or gaseous, can be represented by a linear function of the number of carbon atoms in the normal alkyl radical, provided this number is fairly large, but that this relation does not hold for the first few members of the series. It may be inferred that the heat of formation of a straight-chain polymer molecule will be a linear function of the number of monomer groups in the molecule, provided this number is sufficiently large, but that this relation may not hold for a molecule containing only two or three monomer units. Then the heat of addition of a mole of liquid (or gaseous) monomer to a mole of straight-chain liquid or noncrystalline solid (or gaseous) polymer according to the reaction

$$
m_{n-1}+m=m_{n}
$$

will be a constant, $q$, independent of $n$ if $n>r$, where $r$ is some small integer. If $n \leqq r$ the heat of reaction will, in general, differ from $q$. Let $\left(q+\Delta_{i}\right)$ represent the heat of the reaction

$$
m_{i-1}+m=m_{i} \quad(i \leqq r) .
$$

Then the heat of the reaction

$$
n m=m_{n},
$$

with $n>r$ will be given by

$$
-\Delta H^{\circ}=(n-1) q+\sum_{i=2}^{r} \Delta_{i}
$$

and the heat of polymerization per mole of monomer will be

$$
-\Delta H p^{\circ}=-\Delta H^{\circ} / n=q+\frac{\sum_{i=2}^{r} \Delta_{i}-q}{n} .
$$

If $M_{0}$ and $M$ represent the molecular weights of monomer and polymer, respectively, then eq 5 may be written in the form

$$
-\Delta H p^{\circ}=q+\frac{M_{0}\left[\sum_{i=2}^{r} \Delta_{i}-q\right]}{M} .
$$

From eq 6 it is evident that if $\sum_{i=2}^{r} \Delta_{i}<q,-\Delta H p^{\circ}$

will increase with increasing $M$, as has been shown to be true in the case of ethylene [23]. In order that $-\Delta H p^{\circ}$ shall decrease with increasing $M$ it is necessary that $\sum_{i=2}^{r} \Delta_{i}>y$.

The equation

$$
-\Delta H p^{\circ}=8.424+\frac{2194}{M},
$$

\begin{tabular}{|c|c|c|c|}
\hline \multirow{2}{*}{$M$} & \multicolumn{3}{|c|}{$-\Delta H p^{\circ}$} \\
\hline & Observed & Calculated & $\begin{array}{l}\text { Observed- } \\
\text { Calculated }\end{array}$ \\
\hline $\begin{array}{l}5400 \\
3750 \\
2200 \\
1300\end{array}$ & $\begin{array}{c}\mathrm{kcal} / \text { monomer } \\
\text { unit } \\
8.83 \\
9.04 \\
9.37 \\
10.13\end{array}$ & $\begin{array}{c}\text { kcal/monomer } \\
\text { unit } \\
8.83 \\
9.01 \\
9.42 \\
10.11\end{array}$ & $\begin{array}{c}\text { kcal/monomer } \\
\text { unit } \\
0.00 \\
-.03 \\
+.05 \\
-.02\end{array}$ \\
\hline
\end{tabular}

was derived by the method of least squares from the experimental values of $-\Delta H p^{\circ}$ and $M$ for the four fractions of alpha-methylstyrene polymer. The observed values of $-\Delta H p^{\circ}$ and values calculated from eq 7 are compared in the following tabulation.

The maximum difference between observed and calculated values is seen to be $0.05 \mathrm{kcal}$, which corresponds to about 0.004 percent of the heat of combustion. The standard deviation for $q$ is 0.05 , and for $M_{0}\left(\sum_{i=2}^{r} \Delta_{i}-g\right)$ is 97 . According to eq $7, q=8.4 \mathrm{kcal}$ and $\left(\sum_{i=2}^{r} \Delta_{i}-q\right)=18.6 \mathrm{kcal}$, so that $\sum_{i=2}^{r} \Delta_{i}=27.0 \mathrm{kcal}$. As indicated in the derivation, eq. 5 and 6 are valid only for $n \geqq r$, that is, for values of $n$ such that heat of formation per mole of polymer is a linear function of $n$. The good agreement between the observed and calculated values of $-\Delta H p^{\circ}$ therefore indicates that heat of formation (or combustion) of poly-alphamethylstyrene per mole of polymer is a linear function of $n$, the number of monomer units in the 
molecule ${ }^{8}$ at least for $n \geqq 11$, and it seems probable that this relation would hold for $n>3$ or 4 .

It may be noted that in the derivation of eq 5 and 6 it was tacitly assumed that $n$ and $M$ are constants for any given sample of material, that is, that all of the polymer molecules in a given sample are of the same length. When these equations are applied to polymers containing molecules of various lengths, it can be shown that the proper values of $M$ and $n$ to be used are the number averages, which were actually used in the derivation of eq 7 .

The only 1,1-disubstituted ethylene for which data are available on which a reasonable estimate of $\sum_{i=2}^{r} \Delta_{i}$ for that compound can be based is isobutene. Chemical and X-ray evidence [20, 21], as well as a low heat of polymerization, indicate that the monomer units in the polyisobutene molecule are joined head-to-tail. Evans and Tyrrall [4] have reported for the heat of polymerization of liquid isobutene to liquid polymer the value $12.6 \mathrm{kcal}$ per mole of monomer, and for the heat of dimerization of gaseous monomer to gaseous head-to-taildimer (2,4,4-trimethyl-1-pentene) the value $19.9 \mathrm{kcal}$ per mole of dimer. These values indicate that for isobutene $q=12.6 \mathrm{kcal}$ and $\Delta_{2}=7.3 \mathrm{kcal}$, if the difference between heats of vaporization of polymer and monomer is neglected.

The heat of dimerization of alpha-methylstyrene is not known. If it is assumed to be about the same as that of isobutene, that is, about $20 \mathrm{kcal}$ per mole of dimer, and if $q$ is about $8 \mathrm{kcal}$ as indicated by eq 7 , then $\Delta_{2}$ would be about $12 \mathrm{kcal}$. It would be expected from the fact that steric interference is quite small in a head-to-tail dimer, but is pronounced in the trimer and in polymers of higher molecular weight [4], that $\left(\Delta_{3}+\Delta_{4}+\ldots \Delta_{r}\right)$ would be small in comparison with $\Delta_{2}$, and might even be negative, so that it is unlikely that the value of $\sum_{i=2}^{r} \Delta_{i}$ based on the above assumptions would be much more than half of the value $27.0 \mathrm{kcal}$ derived from eq 7 . However, the fact that the above value of $\Delta_{2}, 12 \mathrm{kcal}$, is greater than the value 8 kcal derived from eq 7 for $q$, suggests that the above assumptions are consistent with a decrease in heat of polymerization with increasing molecular weight of polymer, although they do not lead to quantitative agreement with the observed variation of heat of polymerization with molecular weight. In this connection, it should be emphasized

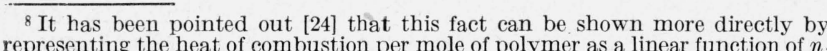
$-\Delta H c^{\circ}\left(25^{\circ} \mathrm{C}\right)$ (solid alpha-methylstyrene polymer) $=A+B n$,

or heat of combustion per monomer unit by the equivalent relation

$$
-\frac{\Delta H c^{\circ}}{n}\left(25^{\circ} \mathrm{C}\right) \text { (solid alpha-methylstyrene polymer) }=\frac{A}{n}+B .
$$

(A determination of the constants in the latter equation by the method of least squares yielded the values $A=-18.56, B=1196.447)$. Combination of the above equation with the value for the heat of combustion of alpha-methylstyren monomer, designated by the symbol $C$, yields the relation

$$
-\Delta H p^{\circ}=C-\frac{A}{n}-B,
$$

which is of the same form as eq 5. However, it is not immediately evident from this derivation how the constant $A$ is related to $q=(C-B)$ and to the end effects, $\Delta_{1}, \Delta_{2}, \ldots$ This relation is given explicitly by the derivation in the text. that some of the assumptions made in comparing alpha-methylstyrene with isobutene are subject to considerable uncertainty.

The estimated effect of the oxygen contents of the polymer fractions on heat of combustion is too small to account for the observed decrease in heat of polymerization with increasing molecular weight.

Although the low values of heat of polymerization of alpha-methylstyrene indicate that the monomer units in the polymer molecule are joined head-to-tail for the most part, there is some reason for conjecturing that the first step in the formation of the polymer molecule may be the tail-to-tail

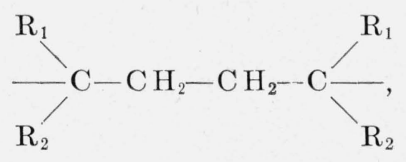

combination of two monomer units, and that the subsequent growth of the molecule is by head-to-tail addition. As stated previously, a model of a polymer molecule with monomer units joined head-to-tail indicates a considerable amount of steric hindrance. A model of a polymer molecule in which two units are joined tail-to-tail, and the others are joined headto-tail to one of the first two indicates only a little steric hindrance in the first three groups. It would therefore be expected that for such a molecule both $\Delta_{2}$ and $\Delta_{3}$ would have fairly large positive values, possibly large enough to bring $\sum_{i=2}^{r} \Delta_{i}$ into quantitative agreement with the value derived from eq 7 .

In regard to whether the initial step in the formation of a 1,1-disubstituted ethylene polymer molecule could be the tail-to-tail combination of two monomer units, it may be noted that Evans and Polanyi [25] have concluded from calculated heats of reaction that in the first step, tail-to-tail addition of isobutene is more probable than head-to-tail addition, and that the latter is more probable than head-to-head addition.

It is believed that the heat of polymerization of alpha-methylstyrene decreases with increasing molecular weight of polymer, as is indicated by the experimental data reported herein. The magnitude of the observed decrease is greater than would be expected from the data on isobutene. The foregoing discussion shows, nevertheless, that the observed change in heat of polymerization with molecular weight is consistent with certain plausible assumptions regarding the structure of the polymer molecule and the heats of the first few steps of the polymerization reaction.

\section{Previous Work}

Auwers, Roth, and Eisenlohr [26] reported for the heat of combustion of alpha-methylstyrene monomer the experimental values 10,183 and 10,194 , mean $10,189 \mathrm{cal} / \mathrm{g}$. By applying appropriate corrections for the value used for heat of combustion of benzoic acid, and by applying the Washburn correction, calculating for weight in vacuum, and correcting to the 
reaction at constant pressure at $25^{\circ} \mathrm{C}$, the mean of the above results may be reduced to a comparable basis with the present work. After these corrections, the above value for heat of combustion becomes $1202.8 \mathrm{kcal} / \mathrm{mole}$

Approximate corrections applied to the value reported by Lemoult [27] give $1209.4 \mathrm{kcal} / \mathrm{mole}$ for heat of combustion of the monomer.

Previous measurements at this Bureau [28] give the value for heat of combustion of liquid alphamethylstyrene $-\Delta H c^{\circ}\left(25^{\circ} \mathrm{C}\right)=1204.3 \mathrm{kcal} / \mathrm{mole}$, with an uncertainty of $\pm 0.4 \mathrm{kcal} / \mathrm{mole}$.

\section{References}

[1] D. E. Roberts, W. W. Walton, and R. S. Jessup, J. Research NBS 38, 627 (1947) RP1801; J. Polymer Sci. 2, 420 (1947).

[2] A. B. Hersberger, J. C. Reid, and R. G. Heiligmann, Ind Eng. Chem. 37, 1073 (1945).

[3] H. M. Stanley, Chemistry \& Industry 1939, 1080.

[4] A. G. Evans and E. Tyrrall, J. Polymer Sci. 2, 387 (1947).

[5] H. C. Dickinson, Bul. BS 11, 189 (1914) S230.

[6] E. F. Mueller, Bul. BS 13,547 (1916) S288.

[7] R. S. Jessup and C. B. Green, J. Research NBS 13, 469 (1934) RP721.

[8] R. S. Jessup, J. Research NBS 29, 247 (1942) RP1499; 36, 421 (1946) RP1711.

[9] R. S. Jessup, J. Research NBS 18, 115 (1937) RP966.

[10] D. E. Roberts and R. S. Jessup, J. Research NBS 40, 281 (1948) RP1873.

[11] E. W. Washburn, BS J. Research 10, 525 (1933) RP546.
[12] M. Shepherd, Anal. Chem. 19, 77 (1947).

[13] Announcement of changes in electrical and photometric units, NBS Circular C459 (1947); also Establishment and maintenance of electrical units, NBS Circular C475 (1949)

[14] Selected values of chemical thermodynamic properties, NBS Circular C500 (1950).

[15] S. G. Weissberg and D. J. Brawley, National Bureau of Standards (unpublished). See R. Signer, Ann. 478, 246 (1930), and G. Gee, Trans. Faraday Soc. 36, 1162 (1940).

[16] W. W. Walton, F. W. McCulloch, and W. H. Smith, J. Research NBS 40, 443 (1948) RP1889.

[17] R. D. Rands, J. L. Prather, R. B. Scott, W. J. Ferguson, and F. G. Brickwedde, National Bureau of Standards (unpublished).

[18] D. E. Roberts, J. Research NBS 44, 221 (1950) RP2073.

[19] P. J. Flory, J. Am. Chem. Soc. 65, 372 (1943).

[20] R. M. Thomas, W. J. Sparks, P. K. Frolich, M. Otto, and M. Mueller-Cunradi, J. Am. Chem. Soc. 62, 276 (1940).

[21] C. S. Fuller, C. J. Frosch, and N. K. Pape, J. Am. Chem. Soc. 62, 1905 (1940).

[22] E. J. Prosen, W. H. Johnson, and F. D. Rossini, J. Research NBS 37, 51 (1946) RP1728.

[23] R. S. Jessup, J. Chem. Phys. 16, 661 (1948).

[24] E. J. Prosen, private communication.

[25] A. G. Evans and M. Polanyi, J. Chem. Soc. London (1947) p. 252.

[26] K. Auwers, W. A. Roth, and F. Eisenlohr, Ann. 385, 102 (1911).

[27] P Lemoult, Compt, rend. 152, 1402 (1911).

[28] E. J. Prosen and W. H. Johnson, National Bureau of Standards (unpublished data, 1946).

Washington, June 6, 1950. 